\title{
SOCIAL STABILITY WITHIN THE NIGERIAN STATE
}

\author{
Charles Chukwuemeka Nweke \\ Nnamdi Azikiwe University, Awka, Nigeria. \\ *http://dx.doi.org/10.4314/ujah.v14i3.9
}

\section{Abstract}

Consistencies about issues relating to human social interaction, mutual awareness, social norm and social order all smack of social stability. Theories addressing social issues abound and remain crucial for the development and advancement of human society. The social stability of any given society could be the result of a process of which commencement was beak and murky but traversed hurdles of varied social problems. As an important factor for political stability, social stability is an ingredient of national sovereignty of which itself is the minor of natural of national identity. The extent to which the content of social stability applies to Nigerian national sovereignty remains focus of the piece. Could Nigeria actually boast of sovereignty with viable social stability? The possible answer produces the question of whether the country is enmeshed in any form of identity crises.

\section{Introduction}

The idea of social stability has over the ages been the concern of disciplines of sociology, socio-political philosophy and political science. The famous sociologist, Emile Durkheim worked to show that every society strives to have stability because social stability creates an even society where there is a social solidarity between the people in one society and they 
work together to make the society better. In the domain of political philosophy, social stability features as a core concern of social contract theories.

The government is well-equipped to overcome both social and political turbulence. It supposed to guarantee citizens its eagerness to create the necessary conditions to improve the quality of life especially social living. Scarce resources, unemployment and unbalanced wealth tend to vitiate a viable social trust but lead to social tensions within political societies and engender loss of credibility to the authority of governments and private organizations. This kind of system failure mostly lends credence to forms of clamour for sociopolitical changes often experienced around the globe. Social instability definitely thrives in social conflicts and crises, thereby leaving an affected society to degenerate to the undesired level of socio-political morass. Thus, when a populace begins to project actions that suggest system dejustification, adequate comprehension of the situation should be attempted as the basic step towards forestalling further socio-political predicaments. For Michael LaBossiere:

One aspect to maintaining social stability is ensuring that people are willing (or forced) to remain within the limits of the stability of the system in question. Naturally, there are important moral questions about the methods that should be used to maintain stability and about whether or not specific systems should be maintained (LaBossiere,2011).

\section{Foundations of Social Stability}

That man is a social being simply means that he does not exists in isolation. He basically exists in relation with others. Social interaction is natural to man and he has no option. The 
sectarian postulation that man is condemned to be free is all inclusive. The freedom of the postulation extends [or finds expression] to man's social nature. He is simply condemned to socialize. This tends to underpin the principle of society or social existence.

If society is understood as "system whereby people live together in organized community," or particular grouping of humanity with shared customs, laws etc..." (Oxford Advanced Learners' Dictionary, 1989). The terms 'social' is about that "...concerning the organization of and relations between people and communities" (Oxford Advanced Learners' Dictionary, 1998). Man's social nature has been the core concern focus of sociologists. Both in Origin of Species and Descent of Man, Charles Darwin vigorously expressed the significance of human social behavior in organic evolution. The reality of society is anchored on man's tendency to come together. Peter Kropotkin reasoned that, "Societies are properly based on a biological propensity to mutual aid" (Cambridge Dictionary of Philosophy, 1995). Thus, organic society is not the product of a rational decision rather a natural tendency. Man is simply thrown into the society and is condemned to relate. At birth, under normal circumstances, a child is born into the family the primary agent of socialization. This initial process of socialization is epistemological. Thus, "The lifelong process of learning begins shortly after birth. Since newborns can hear, see, smell, taste and feel heat, cold, and pain, they are constantly orienting themselves to the surrounding world. Human beings, especially family members, constitute an important part of their social environment" (Schaefer, 2003:94-5). The child grows into a wilder society beginning with the immediate community through interactions in fronts of formal education to terrains of their social possibilities. 
Sociologists have hinged their primary focus on "...the influence of social relationships on people's attitudes and behavior and on how societies are established and change" (Ibid, 5). Relying on an unusual type of creative thinking, sociological magi ration, that is, an awareness of the relationship between a person and the broader society, the understanding of human social behavior is made possible. Man's social existence becomes more pronounced and makes deeper meaning the context of a wider society, the state.

\section{The Social Foundation of the Polity}

The state as an organized political institution is not natural to man. It rather sprung out of the need for better organization of society. Although man possesses a political nature, meaning that the tendency to be the political is inherent in him, at the pre-political era, that is, prior to the sought of common good, he existed on the plains of social relations with the natural instinct of self-preservation. The Hobbesian state of nature, although theoretical, is not a political but a social state where individuals and groups of individuals relate to one another with uncontrolled selfish passions for supremacy, possessions and glory resulting in social war motion (friction). The escape to the precarious situation was the necessity of a commonwealth, the unit society or political state. Hobbes' whole idea of the state of nature and the any society is captured thus:

In this state, the outcome of one's productive effort is always uncertain, and life is solitary, poor, nasty, brutish and short. To avoid this intolerable situation, the law of nature, which dictates self-preservation commands men to surrender this liberty to a single sovereign. By covenanting, or contracting, to lend their force to the sovereign's endeavours, they first create the conditions under which the enforcement of laws, and so 
too the institutions of property and injustice, are possible. Thus is born leviathan, the great artificial being of the commonwealth, whose very soul is sovereignty (Cahn, 1990:445).

In the view of Sabine and Thorson, the state is the product of social classes, body of citizens of various levels and strata. Prior to the era of political institutions, "... the political problem was to discover what place each and of class of men of merited in a wholesome society so constituted that all the significant sorts of social work could go on" (Sabine \& Thorson, 1989:21). Marx had stated that, the state, when primarily considered as a power that organizes the society, presupposes man's inevitable alienation from the institution. For him, "...it is the structure of society which gives rise to the state" (Marx, 1956:5). Simply put, the state is the product of social contract and the political activities within the state are all geared towards a more refined social living (social stability). Hence, political life basically assumes social characteristics. D.A. Falade, and T.A. Ekundayo considered that:

Social Stability is a fundamental requirement for national development. It is a state of social cohesion; understanding and cordial relationship among the citizens, Social stability takes place when the citizens, regardless of their religious, social and ethnic backgrounds, have peaceful co-existence and mutual understanding (Falade \& Ekundayo).

\section{Nigeria Social Stability}

A critical view at the Nigerian society calls to question the extent to which interacting individuals and inherent social institutional have engendered and foster a healthy social existence. Apart from the families and local communities, 
Nigeria is a multi-ethnic nation. A Nigerian professor of history, Ifeyinwa Emejulu accounted that:

This country (Nigeria) is inhabited by about 250 ethnic groups and has large kingdom with distinct customs, traditions and languages. The lager and politically dominant groups include the Yoruba, the Igbo and the Hausa. Other cultural groups include the Idoma, the Efik, Ibibio, the Tiv, the Nupe, the Kaanuri, the Ijaw, the Igala and the Jukun etc (Emejulu, 2001).

Every human society harbours a culture in so far as it has values systems, religious practices, belief, customs and traditions handed on from generation to generation. An ethnic group is a distinct people with specific culture which differentiate it from another group. As a multi-ethnic entity, Nigeria is also a multi- cultural nation. Culture remains a major content of socialization. This means that socialization within a given society entails inter-behavioural conformity to peculiar cultural demands and expectations of the society. Ezeokana views culture and socialization as interdependent psychological principles for defining a society. For him, "...culture provides the content of the material in which people will learn and internalize, and socialization on the other hand, helps in passing over the evolved cultures down from generation to generation thereby making cultures to be enduring and sustaining" (Ezeokana, 2010).

This understanding is fundamental and forms a veritable foundation for a meaningful outlay of the idea of civic responsibility. Adherence to civic responsibility which includes loyalty to the community and the state, obedience to rules and regulations, participation in the political process, respect for the rights of others and helping to prevent crime is cardinal to any nation's social stability. A society could be termed socially stable if it could boast of a considerable level 
of harmonious social relations. Social welfare services are also important for a viable social stability.

In Nigeria, social welfare services are not a new phenomenon. The traditional settings provided social welfare services through the elders, title holders, traditional rulers, family heads, age grades, traditional religious leaders, etc. These institutions were responsible for the maintenance of discipline and settlement of disputes in the community and they also offered rewards where appropriate. The communities were highly structured to handle cases of deviance. Minor disputes were usually settled by family heads while serious cases were referred to village heads or traditional rulers for settlement. However, formal social work started in Lagos in 1940s during the Second World War when there were many stray and abandoned children and juveniles in the streets (SDPN: 1992). The services later spread to other parts of the country. The main components of Social Welfare Services in Nigeria are family and child welfare, rehabilitation, counseling, corrections and care of the elderly.

In the Nigerian context, there is sometimes the basic problem of intra ethnic harmony, due to further internal cultural polarity. For instance, the Igbo nation is replete with initial ethnic divisions of peoples with specific customs and traditions with many linguistic dialects. The bid to protect socio-political interests often times result in intra-ethnic conflicts. When the interest extends to the inter-ethnic level, intra-ethnic harmony is pursued at the expense of national cohesion resulting in tribal conflicts and social crises. D.A. Falade, and T.A. Ekundayo had noted that, "One of the causes of conflicts and social crises in Nigeria is the low level of civic responsibilities among the citizens" (Falade \& Ekundayo). They continued that: 
Falade (2007), expressed that the low level of civic responsibilities accounted for the truncated sociopolitical state of the nation. Insurrections, election rigging, corruption and violation of human rights are some of the consequences of low level of civic responsibilities in Nigeria (Falade \& Ekundayo).

That is the problem of the Nigerian state. Ranging from ethnic struggle to all forms of restiveness, the Nigerian spirit boils. Thus, Nigeria social stability remains bleak and further balkanizes its political stability. The current Nigerian security challenges mainly posed by the Muslim fundamentalist groups (Boko Haram and Ansaru) of the Northern Nigeria, upon critical consideration, amount pose greater jeopardy danger to the Nigerian National identity. Despite the bulk of resources already committed to address the trend, the situation does not yet seem to abate.

\section{Measures towards Sustainable Nigeria Social Stability}

Adequate disposition to socio-cultural values in Nigeria ought to be the cardinal objective of public social orientation. This is a prerequisite for the right attitude towards civic responsibility. D.A. Falade, and T.A. Ekundayo Submitted that:

To ensure social stability, every citizen needs to acquire and demonstrate appropriate civic attitudes and skills. There is need for both the male and female citizens to acquire and demonstrate the values and traits of civic responsibilities as a means of ensuring social and political stability(Falade \& Ekundayo).
Aldous Huxley in his novel entitled Brave New World conceived of a state of which stability is dependent on individual stability. Individual stability entails the definition of individual identity within the context of the community. 
Thus with "Community, Identity, Stability," as the state's motto, these conditions produces a world where people are finally living "happily ever after," but at a great cost.

Ricky Gehlhaus considered that:

The key ingredient to stability that the novel implies is that individuality must be absent. The government in Brave New World understands that fact and in the worlds of one of the ten controllers of the world states, "[there is] no civilization without social stability. No social stability without individual stability" (Huxley 28). The need for stability creates a government which, "believes that stability can be achieved if people think and look the same," (Fan 1). Stability, in effect, demands robots, not people (Gehlhaus, 1998).

Huxely's theory simply draws attention to reconsideration for African communalism whereby the identities of inhabiting individuals find expression and make meaning within the context of the community. As such, the stability of such society is dependent on the level the operating principles are upheld. To this effect, Nigeria can revamp its social stability by the adoption of the principles of communalism which tend to bind people together in African brotherhood. Such principle will simply collapse the politics and social relations of ethnic consciousness.

Appropriate social development policies and structures are also requisite for a healthy Nigeria socio-political existence. For Okunlola, social development is, “...the greater capacity of the social system (social structure, institutions, services, \& policy) to utilize resources to generate changes in levels of living, interpreted in the broad sense as related to accepted social 
values \& a better distribution of income, wealth \& opportunities" (Olubowale, 2010). How this translates into the Nigerian social policy can be captured that the Nigerian National Advisory Committee on Social Development (NACSD) in 1975 identified as social development, the subjects of social welfare, women program, sport development, \& community development. Meanwhile, according to Gbolahan Olubowale, Broad National Goals of Social Development Policy in Nigeria include:

The continuous improvement of the quality of life of the entire citizens of the country, as groups \& individuals.. The promotion and continuous improvement of initiatives \& programs aimed at improving the welfare of the society's most vulnerable $\&$ disadvantaged groups, notably the disabled; the poor $\&$ destitute; the aged; children; youth; rural populations \& women. The development and mobilization of human \& social capacity; in particular, the strengthening of the capacity of various institutions, communities \& target groups to cope creatively \& effectively with the challenges of change. The anticipation, control and minimization of social problems. The maintenance of high moral standard of the nation as a well as alertness and responsive action against policies \& trends both foreign and local that militates against such standard. The maximization of the contribution of the Social Development Sector towards the attainment of the country's socioeconomic integration \& human development objectives The promotion of policy orientations likely to strengthen the observance $\&$ protection of human rights, to advance social justice \& human dignity \& 
enhance the status of people in the scheme of national development (Olubowale, 2010).

But then, the problem is that of the dichotomy between theory and praxis, that between policy enactment and implementation. Thus, if the objective principles upon which national stability can be established in a political entity are basically absent, then the result is simply obvious. The present Nigeria security situation accentuates this position and tends to drift the Nation state into some form of crises of identity with regard to its sovereignty. The persistent agitations of the various ethnic nationalities for autonomy and independence from the present Nigeria which takes multi-faceted forms continue to deepen the cracks on Nigeria's wall of unity. A consideration is apt to the possible factor that informed the United States' prediction of Nigeria's disintegration by 2015. But then, the socialpolitical events as they evolve in the country over the last decade tend to navigate towards the actuality of the prediction.

\section{Conclusion}

Attempts have been made in this piece to touch on various aspects of social stability basically as a socio-political concept. Emphasis ought to be continually laid, as a matter of objectivity, on the factors promoting or vitiating social stability in Nigeria. In so far as social relations among Nigerians are approached from the lens of ethnicity, Nigerian unitary identity remains theoretical. But then, a pessimistic approach to the whole project will foreclose meaningful produces on critical issues of sort. 


\section{Works Cited}

Audi, R (ed), The Cambridge Dictionary of Philosophy, Cambridge: Cambridge University Press, 1995

Cahn, S. M. Classics of Western Philosophy, Indianopolis: Hackett Publishing Company, Inc., 1990

Cowie, A. P. (ed),Oxford Learners' Advanced Dictionary, $4^{\text {th }}$ ed, Oxford: Oxford Univrsity Press, 1989

Falade, D. A. and Ekundayo, T. A. ,Social Stability and the Effects of Gender Differences in the Demonstration of some Civic Traits among Secondary School Students in Ondo State, Nigeria, C:IUsers $|C l i e n t| D o w n l o a d s \backslash S O C I A L$ STABILITY.doc 26/4/2013

Gehlhaus, R. Brave New World: The Cost of Stability, http://somaweb.org/w/sub/BNW_CostOfStability. html, 1998, Accessed 14/4/2013

Marx, Karl, Selected Writings in Sociology and Social Philosophy, trans by T. B. Bottomore, New York: McGrawHill Book Company, 1956.

LaBossiere, Michael, (2011) Social Stability

http://aphilosopher.wordpress.com/2011/04/21/socialstability/ Accessed 14/4/2013

Olubowale, G. Social Work and Social Development in Nigeria - Issues and Challenges, 
http://www.slideshare.net/guestdfeaacd/social-work-andsocial-development-in-nigeria-issues-challenges, Accessed $14 / 4 / 2013$

Sabine G. H. and Thorson, T. L., A History of Political Theory, Forth Worth: Harcourt Brace College publishers, 1989

Schaefer, R. T., (ed), Sociology, New York: McGraw-Hill, 2003 